\title{
Fire Resistance and Seismic Performance Study of a High-Strength Construction Steel Using Creep and Internal Friction Analysis
}

\author{
Zhenlin Xu ${ }^{1}$, Lei Yang ${ }^{1}$, Xiaojie Du ${ }^{1}$, Zhaodong $\mathrm{Li}^{2}$, Zhongmin Yang ${ }^{2}$, Xiquan Jia ${ }^{1}$ and Yizhu He ${ }^{1, *(\mathbb{C})}$ \\ 1 School of Materials Science and Engineering, Anhui University of Technology, Ma'anshan 243002, China; \\ xz12015@ahut.edu.cn (Z.X.); yanglei2010@ahut.edu.cn (L.Y.); duxiaojie@ahut.edu.cn (X.D.); \\ jiaxiquan@ahut.edu.cn (X.J.) \\ 2 Department of Structural Steels, Central Iron and Steel Research Institute, Beijing 100081, China; \\ cisri_lizhaodong@126.com (Z.L.); yangzm2005@126.com (Z.Y.) \\ * Correspondence: heyizhu@ahut.edu.cn
}

Citation: Xu, Z.; Yang, L.; Du, X.; Li, Z.; Yang, Z;; Jia, X.; He, Y. Fire Resistance and Seismic Performance Study of a High-Strength Construction Steel Using Creep and Internal Friction Analysis. Metals 2021, 11, 1045. https://doi.org/ 10.3390/met11071045

Academic Editor: Hannu Hänninen

Received: 30 May 2021

Accepted: 28 June 2021

Published: 29 June 2021

Publisher's Note: MDPI stays neutral with regard to jurisdictional claims in published maps and institutional affiliations.

Copyright: (c) 2021 by the authors. Licensee MDPI, Basel, Switzerland. This article is an open access article distributed under the terms and conditions of the Creative Commons Attribution (CC BY) license (https:// creativecommons.org/licenses/by/ $4.0 /)$.

\begin{abstract}
Fire resistance and seismic performance are the two of the most important considerations for the design of construction steel. The fire resistance of the high-strength construction steel, Q460FRE, which contains low Mo, was investigated by means of creep test under different experiment conditions. Then, the seismic performance of the Q460FRE steel, after being subjected to various fire temperatures, was characterized by internal friction analysis. The Q460FRE steel exhibited excellent fire resistance, and the yield strength at $600{ }^{\circ} \mathrm{C}$ was $67.4 \%$ of the yield strength at room temperature. The constitutive equation of creep stress and fracture time at $600{ }^{\circ} \mathrm{C}$ was established. The bearing tensile stress of the Q460FRE steel should be lower than $337 \mathrm{MPa}$ to ensure at least $1 \mathrm{~h}$ to evacuate from the fire. The creep stress and alternating temperature significantly affected the serration behavior of the creep strain. The internal friction analysis indicated that the seismic performance of the Q460FRE steel decreased with the increase in fire temperature, being consistent with the analysis results of the seismic performance characterized by the yield ratio.
\end{abstract}

Keywords: fire-resistant steel; seismic performance; creep; internal friction; mechanical property

\section{Introduction}

With the rapid development of the construction industry, higher requirements have been put forward for the strength, service life and safety of construction steel. Natural disasters such as earthquake and fire would cause devastating damage to buildings. Therefore, fire resistance and seismic performance are the two major problems that need to be solved urgently for building steel. Meanwhile, low cost and green environmental protection have become the development direction of construction steel in order to achieve the purpose of low carbon economy: saving raw materials and energy, as well as reducing emissions.

In general, the yield strength of conventional structural steels at $600{ }^{\circ} \mathrm{C}$ will drop to less than $50 \%$ of the yield strength at room temperature, thus losing their bearing capacity [1-3]. Although fire-resistant coating can improve the fire resistance of steel structure, it will add to the manufacturing cost and pollute the environment [4,5]. Therefore, improving the fire resistance of steel itself is the most effective approach to increase the fire resistance capacity of buildings. The main idea of alloying traditional fire-resistant steel is to add a high molybdenum (exceeds $0.5 \mathrm{wt} . \%$ ) and improve the high-temperature performance of steel by the solid solution and precipitation strengthening of Mo [6]. However, the high content of Mo significantly increases the cost of the alloy. In recent years, the composite microalloying of $\mathrm{Nb}, \mathrm{V}$, Ti and low $\mathrm{Mo}(\leqq 0.3 \%)$ has provided a feasible and economical means for the design of fire-resistant steel [7-9]. A high-strength fire-resistant construction steel Q460FRE containing high $(\mathrm{Nb}+\mathrm{Ti})$ and low Mo microalloying was developed. In the 
case of fire, the yield strength of fire-resistant steel at $600{ }^{\circ} \mathrm{C}$ should reach more than $2 / 3$ of the yield strength at room temperature $[10,11]$. Previous investigations have focused on the microstructure and tensile properties of fire-resistant steel at elevated temperature [12-14]. Unfortunately, their creep behavior, which can serve as a significant standard to evaluate reliability and safety under high temperature and load conditions $[15,16]$, has not been studied systematically thus far.

The design of fire-resistant steel should also consider the seismic performance to avoid catastrophic earthquake damage to the steel structure. The seismic performance of steel is usually characterized by the yield ratio [17]. A low yield ratio means that steel can produce plastic deformation in a wide range, thus absorbing seismic energy and improving the seismic performance of steel structures [18]. In addition, internal friction represents the damping capacity of material against vibration, and it is related to atomic and magnetic rearrangements within the material [19]. The higher the internal friction value, the vibration energy consumption capacity of the steel itself, generating better seismic performance [20].

In this study, the fire resistance and seismic performance of a high-strength construction steel Q460FRE were investigated using creep and internal friction test. In order to study the fire resistance of the Q460FRE steel, the Gleeble-3500 thermal simulation testing machine (DSI, St. Paul, MN, USA) was used to evaluate the effect of constant load at $600{ }^{\circ} \mathrm{C}$ and alternating temperature on the creep behavior. Then, the internal friction test was carried out after the steel held at $250{ }^{\circ} \mathrm{C}$ to $600{ }^{\circ} \mathrm{C}$ for $1 \mathrm{~h}$ to analyze the seismic performance of the steel after a fire. Moreover, the relationship between internal friction value and yield ratio was discussed.

\section{Materials and Methods}

\subsection{Test Steel}

All test specimens were cut from a thermo-mechanically controlled processed (TMCP) Q460FRE steel sheet with a thickness of $20 \mathrm{~mm}$. The chemical composition of the Q460FRE steel was analyzed by X-ray fluorescence spectrometer (BRUKER D8 Advance, Karlsruhe, Germany), as shown in Table 1. The microstructures of the Q460FRE steel composed of ferrite, bainite and martensite-austenite (MA) constituent are shown in Figure 1. Bainite is beneficial to increase the strength of the Q460FRE steel.

Table 1. Chemical composition of the Q460FRE steel.

\begin{tabular}{ccccccccc}
\hline $\mathbf{C}$ & $\mathbf{S i}$ & $\mathbf{M n}$ & $\mathbf{C r}$ & $\mathbf{N i}$ & $\mathbf{C u}$ & $\mathbf{M o}$ & $\mathbf{T i}$ & $\mathbf{N b}$ \\
\hline 0.045 & 0.25 & 1.00 & 0.50 & 0.48 & 0.30 & 0.26 & 0.015 & 0.040 \\
\hline
\end{tabular}

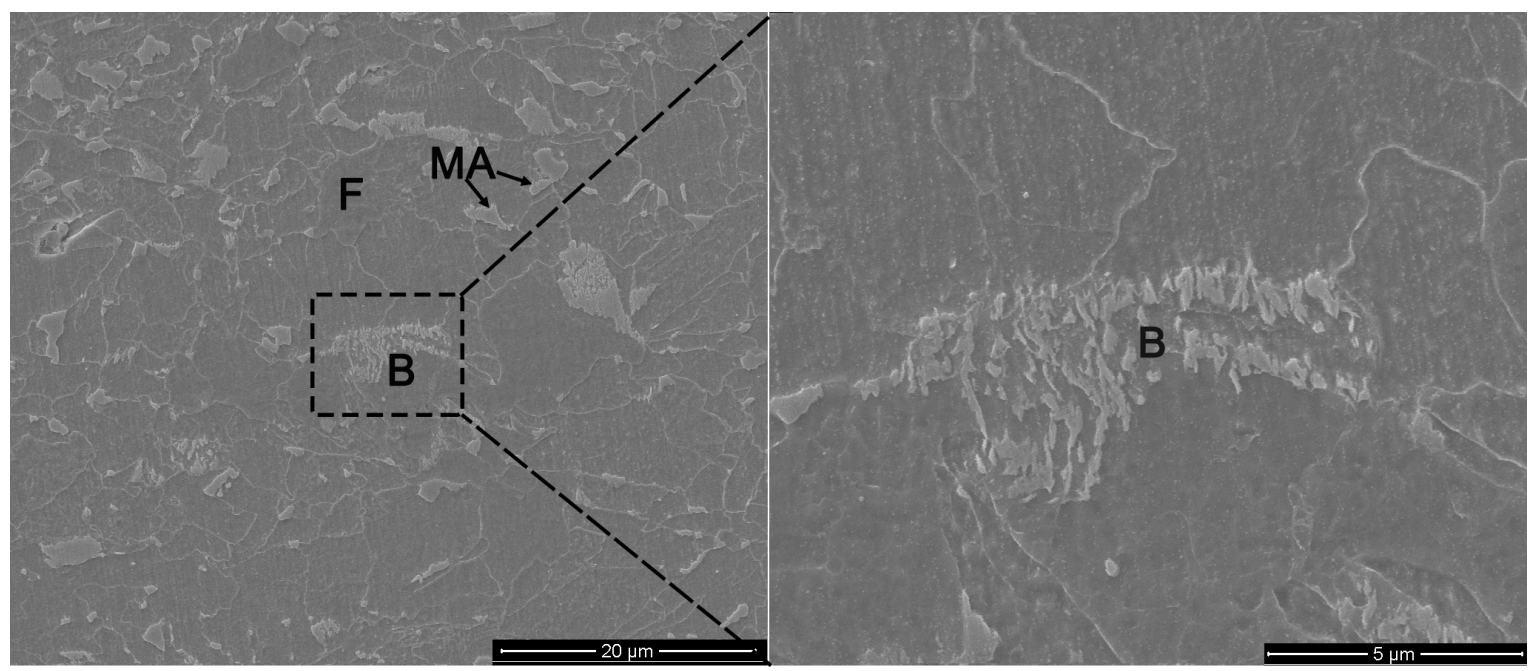

Figure 1. Microstructure of the TMCP Q460FRE steel. 


\subsection{Microstructural Characterizations}

The microstructures of the specimens were characterized by a field-emission scanning electron microscope (FESEM, Tescan MIRA3 XMU, Brno, Czech Republic). Specimens for FESEM were prepared by mechanical polishing and following by eroded with $4 \%$ nitric acid alcohol.

\subsection{Creep Test}

Cylindrical bar tensile specimens with a gauge length of $40 \mathrm{~mm}$ and a diameter of $6 \mathrm{~mm}$ (Figure 2) were used in this study. The constant load creep test was carried out with a Gleeble-3500 thermal simulation testing machine at $600^{\circ} \mathrm{C}$ in a vacuum (the vacuum value was $0.1 \mathrm{~Pa}$ ), as shown in Figure 3. The constant tensile stress values were $184 \mathrm{MPa}, 210 \mathrm{MPa}$, $263 \mathrm{MPa}$ and $316 \mathrm{MPa}$, respectively. The fracture morphology of the tensile specimens was observed by a FESEM.

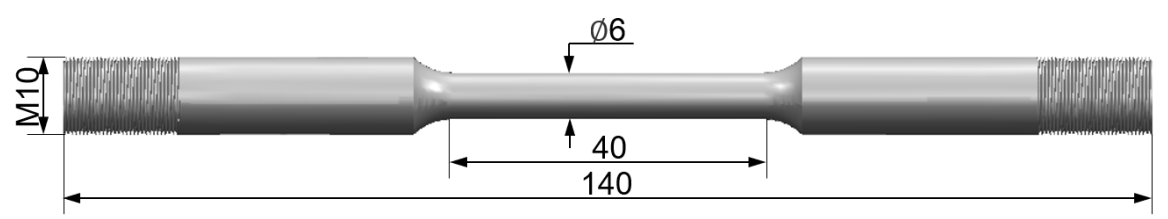

Figure 2. Schematic diagram of the specimen (unit: $\mathrm{mm}$ ).

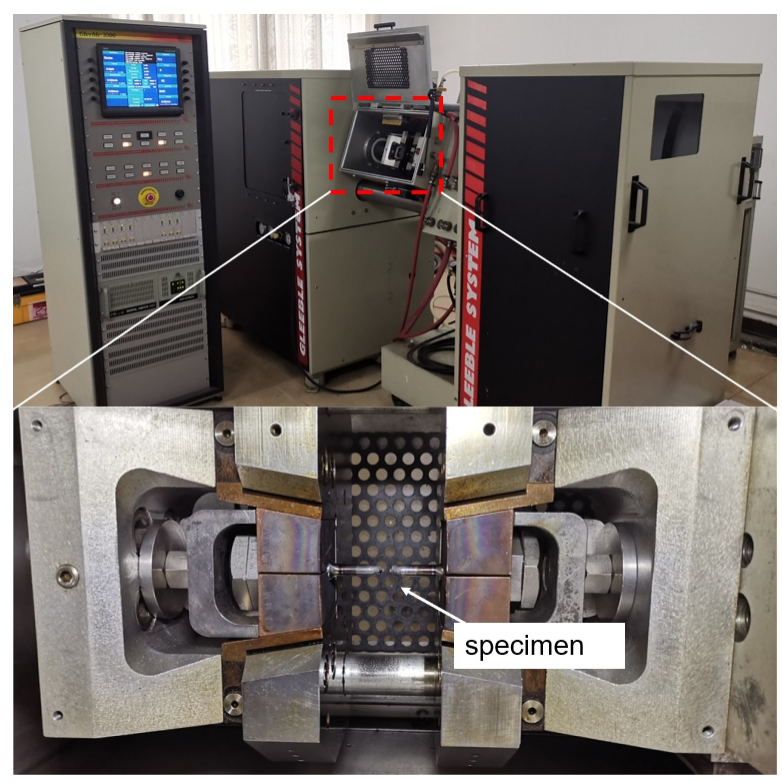

Figure 3. Test device: Gleeble 3500 thermal simulation testing machine.

The constant stress (263 MPa) creep test under heating and cooling cycles was carried out to evaluate the deformation behavior of steel at alternating temperature. The temperature varied between $200{ }^{\circ} \mathrm{C}$ and $600{ }^{\circ} \mathrm{C}$, with a heating rate and a cooling rate of $28.6^{\circ} \mathrm{C} / \mathrm{s}$ and $10^{\circ} \mathrm{C} / \mathrm{s}$, respectively.

\subsection{Internal Friction Test}

The internal friction (IF) test was conducted on an MFP-1000 multifunctional internal friction apparatus (Hefei, China) to analyze the seismic performance of the Q460FRE steel after a fire. After holding in the $250-600{ }^{\circ} \mathrm{C}$ temperature range for $1 \mathrm{~h}$, the IF specimens were processed into $70 \mathrm{~mm} \times 1.8 \mathrm{~mm} \times 1.2 \mathrm{~mm}$ by wire cutting and then mechanically polished with 1200 grit emery paper. 


\section{Results and Discussion}

\subsection{Tensile Properties}

The typical engineering stress-engineering strain curves of the Q460FRE steel under room temperature $\left(25^{\circ} \mathrm{C}\right)$ and $600{ }^{\circ} \mathrm{C}$ are depicted in Figure 4 . It shows that the strength of the Q460FRE steel decreased with the increase in temperature, while the elongation underwent an increase as the temperature raised. When the temperature of the tensile test increased from $25{ }^{\circ} \mathrm{C}$ and $600{ }^{\circ} \mathrm{C}$, the yield strength decreased from $463 \mathrm{MPa}$ to $312 \mathrm{MPa}$, with a decrease of $32.6 \%$. Moreover, the elongation increased from $22.2 \%$ to $45.6 \%$, with an increase of up to $105 \%$. The decrease in strength at elevated temperature is related to the following factors [21]: (1) the movement of dislocations (slip and climb) leads to the occurrence of plastic deformation; (2) the growth of grain and coarsening of carbide precipitated phase lead to the dislocation easier to move; (3) grain boundary sliding. Particularly, when the drawing temperature rises above $400{ }^{\circ} \mathrm{C}$, flow stress reduces dramatically, leading to a sharp decline in strength [22].

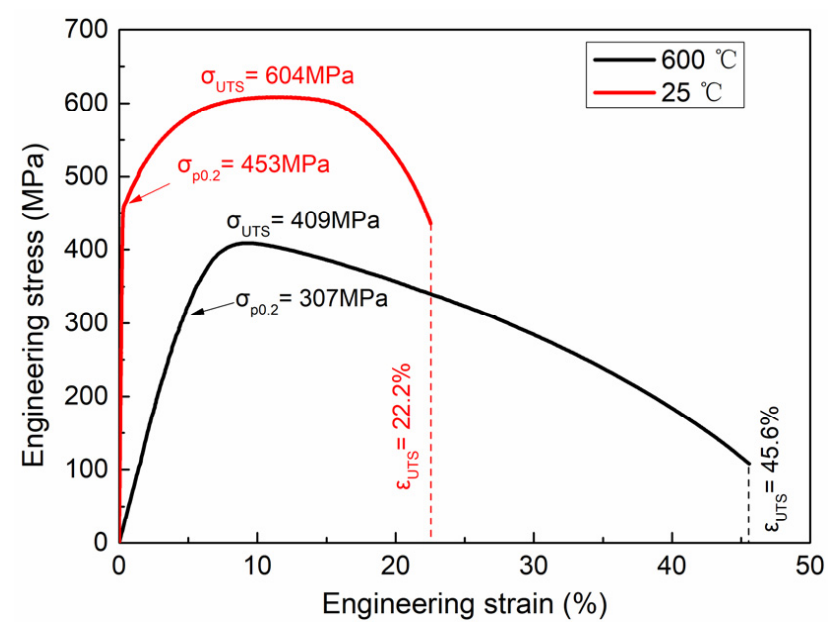

Figure 4. The engineering stress-strain curves of the Q460FRE steel.

In a previous study, the yield strength of the conventional structural steel and the fire-resistant steel was $495 \mathrm{MPa}$ and $544 \mathrm{MPa}$, respectively, at room temperature, and their yield strength dropped to $204 \mathrm{MPa}$ and $287 \mathrm{MPa}$, respectively at $600{ }^{\circ} \mathrm{C}$ [2]. In this work, compared with the room temperature tensile, the yield strength decreased by less than one third at $600{ }^{\circ} \mathrm{C}$, which indicated that the tensile properties of the Q460FRE steel complied with the design requirements of fire-resistant steel. Nanoscale carbide particles were not easy to precipitate during the TMCP process. However, large amounts of nanoscale carbide particles precipitated at elevated temperature, which played a good role in precipitation strengthening, thus significantly improving the high-temperature strength of fire-resistant steel [23].

\subsection{Evaluation of the Fire Resistance Utilizing Creep Test}

The creep strain evolution during various uniaxial tensile stress creep tests at $600{ }^{\circ} \mathrm{C}$ is plotted in Figure 5. When the creep stress was less than $263 \mathrm{MPa}$, the specimens have not fractured after the $2 \mathrm{~h}$ creep test. The creep strain that occurred increased from $0.20 \%$ to $2.27 \%$, with the creep stress increasing from $184 \mathrm{MPa}$ to $263 \mathrm{MPa}$. The creep strain-time curves presented two obvious stages [24]. In the primary creep stage, the creep strain increased sharply, which was defined as the transient creep stage. Then, the creep strain fluctuated within a small range during the steady creep stage. When the creep stress rose to $316 \mathrm{MPa}$, the creep curve presented a third stage: accelerated creep, during which the creep strain rate increased sharply until the specimen fractures, as shown in Figure $5 \mathrm{~d}$. The specimen suddenly fractured after about 74 min of stretching. 

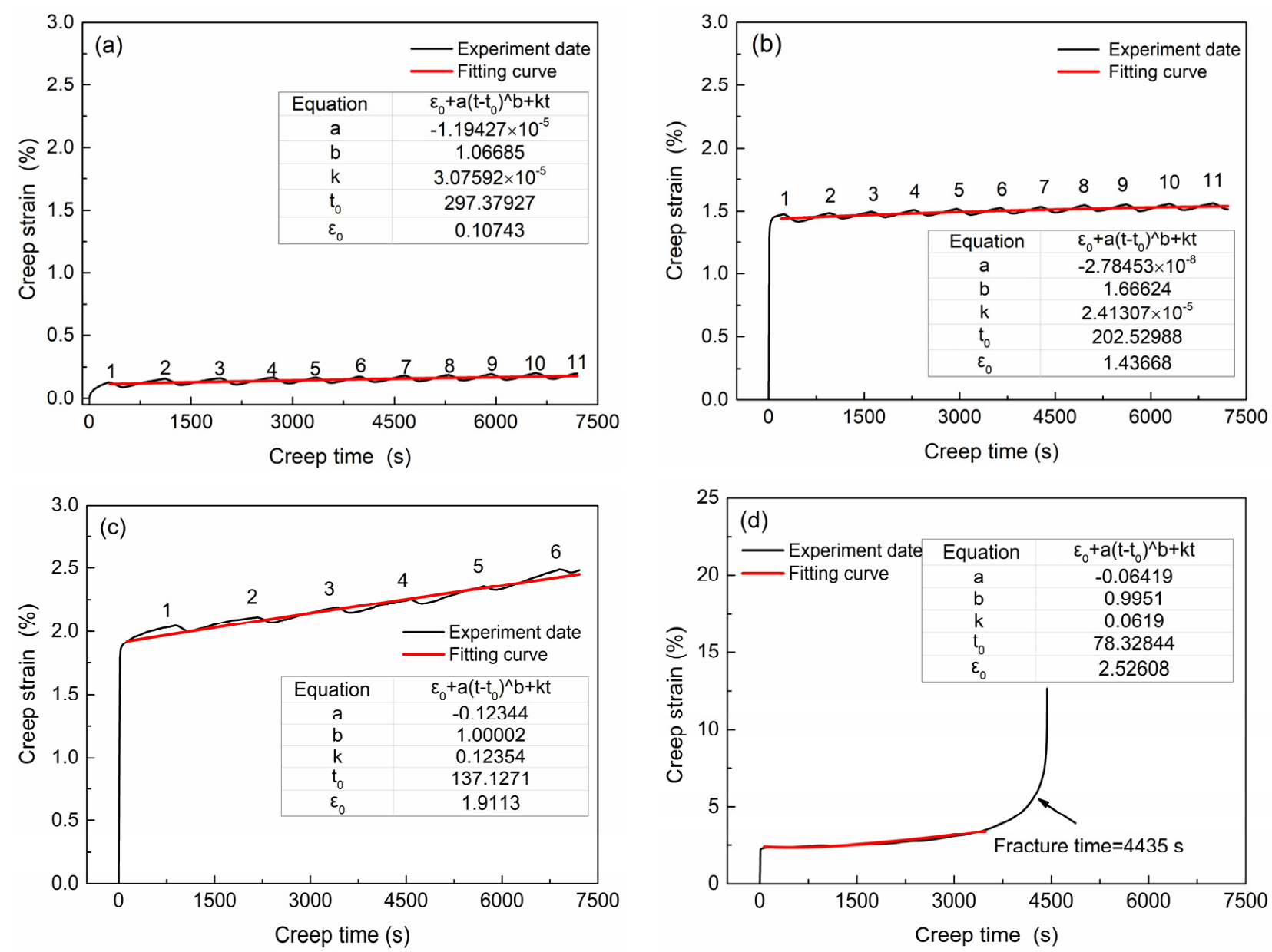

Figure 5. The creep strain evolution during various uniaxial tensile stress creep tests at $600{ }^{\circ} \mathrm{C}:(\mathbf{a}) 184 \mathrm{MPa}$, (b) $210 \mathrm{MPa}$, (c) $263 \mathrm{MPa}$, (d) $316 \mathrm{MPa}$.

Normally, the creep displacement-holding time curve could be fitted by an empirical fitting equation $[25,26]$ :

$$
h=h_{0}+a t^{b}+k t
$$

where $h_{0}$ denotes the displacement at the beginning stage of the creep, and $a, b$ and $k$ are fitting constants. In this study, the relationship between creep strain and time during the steady-state creep stage could be fitted according to the following formula:

$$
\varepsilon=\varepsilon_{0}+a\left(t-t_{0}\right)^{b}+k t
$$

where $\varepsilon_{0}$ and $t_{0}$ refer to the creep strain and time at the beginning of the steady-state creep stage. In general, at a certain temperature, the relationship between the steady-state creep strain rate $(\dot{\varepsilon})$ and the creep stress can be expressed by the following formula [27]:

$$
\dot{\varepsilon}_{m}=A \sigma^{n}
$$

where $A$ is a constant related to material properties and temperature; $n$ refers to the stress index of steady-state creep. Based on the experimental data of creep test, Figure 6a presents the function relation between $\dot{\varepsilon}$ and $\sigma$, and the equation of the regression line is as follows:

$$
\ln \dot{\varepsilon}_{m}=6.26 \ln \sigma-48.92
$$



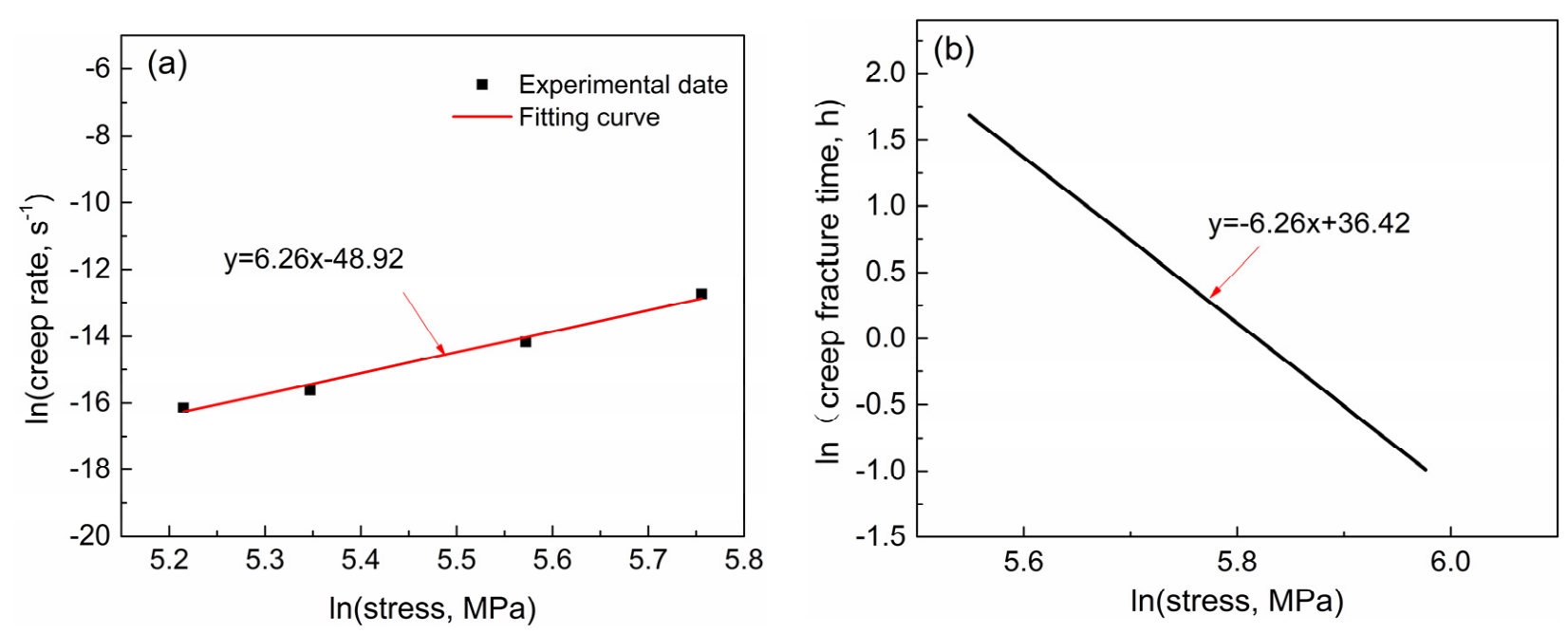

Figure 6. (a) Variation of the $\ln -\ln$ plots of steady-state strain rate curve vs. creep stress. (b) Variation $\ln -\ln$ plots of creep fracture time curve vs. creep stress.

It can be concluded that the steady-state creep stress index (n) of Q460FRE was 6.26. The $\mathrm{n}$ is widely used to analyze the creep deformation mechanism [28]: $\mathrm{n}=1$ corresponding to diffusion creep; $\mathrm{n}=2$ for grain boundary sliding; $\mathrm{n}=3-8$ for dislocation glide or climb mechanism. It indicates that the creep deformation of the Q460FRE steel was controlled by dislocation motion at $600{ }^{\circ} \mathrm{C}$.

The creep fracture time $\left(t_{r}\right)$ can be derived according to Monkman-Grant's mathematical equation [29]:

$$
\dot{\varepsilon}_{m} \times t_{r}^{m}=C
$$

where $C$ is a material constant independent of creep stress and temperature and $m$ is a constant approximately equal to 1 . In this study, the value of $\dot{\varepsilon}$ was $1.05 \times 10^{-2} \mathrm{~h}^{-1}$ under the creep stress of $316 \mathrm{MPa}$. Combining Equation (4), the relationship between $\dot{\varepsilon}$ and $\sigma$ can be described as:

$$
\ln t_{r}=-6.26 \ln \sigma+36.42
$$

Figure $6 \mathrm{~b}$ presents the variation of the $\ln -\ln$ plots of $t_{r} v s$. $\sigma$. Usually, fire-resistant steel needs to be carried for 1-3 $\mathrm{h}$ in a fire without breaking, to ensure that personnel have enough time to escape. It can be calculated that the critical creep stresses of the Q460FRE steel for $t_{r}=1 \mathrm{~h}$ and $t_{r}=2 \mathrm{~h}$ at $600{ }^{\circ} \mathrm{C}$ were $337 \mathrm{MPa}$ and $282 \mathrm{MPa}$, respectively, i.e., $72.8 \%$ and $60.9 \%$ of the yield strength at room temperature.

It is found that the creep stress significantly affects the serration behavior of the creep strain during the secondary creep stage. When the creep stress increased from $184 \mathrm{MPa}$ to $263 \mathrm{MPa}$, the fluctuation period of the creep strain showed a prolonged trend. When the stress was less than $210 \mathrm{MPa}$, the creep strain had eleven peak values, and the creep strain had six peak values under the creep stress of $263 \mathrm{MPa}$. When creep stress increased to $316 \mathrm{MPa}$, no obvious serration shape was observed. Figure 7 shows the curve of creep strain peak interval evolution under the creep stress of $184 \mathrm{MPa}$. It illustrates that the strain peak interval was between $850 \mathrm{~s}$ and $600 \mathrm{~s}$. The strain peak interval decreased with creep time, and the rate of decline gradually slowed down.

The serration behavior is related to the dislocation-solute interactions and dislocationprecipitate interactions [30]. Dislocations distort the lattice, causing an elastic stress field that acts on nearby solute atoms. When a movable dislocation is being blocked, a solute cloud possibly forms around it, and the movable dislocation is fastened. Nano-scale precipitates in the steel can also pin dislocation [31]. Under the action of external stress, dislocation may overcome these obstacles by thermally activated motion. Moreover, in low-carbon steels, the interstitial atoms $(\mathrm{C}$ and $\mathrm{N})$ distributed near the core of dislocations could release the lattice distortion or atomic-level stress. Thereby, the serration behavior 
was derived from the repeated action of the moving dislocations, were pinned by diffusing solutes and precipitates, and then broke free from this pinning.

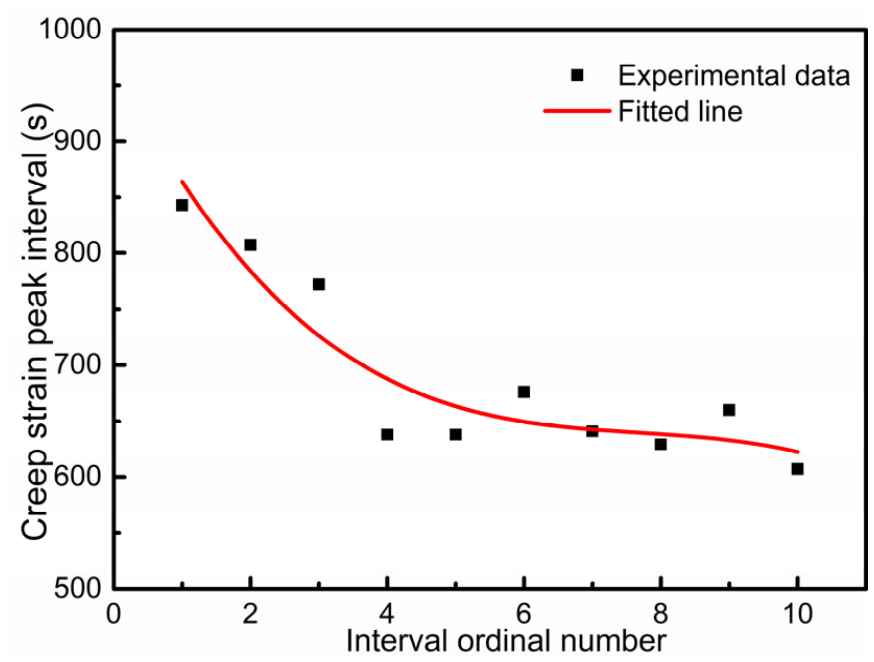

Figure 7. Curve of creep strain peak interval evolution under the tensile stress of $184 \mathrm{MPa}$.

The microstructure type of the Q460FRE steel did not change after the creep test, still composed of ferrite, bainite and MA constituent, as shown in Figure 8. However, compared with the TMCP specimen, the MA constituent in creep specimens decomposed and became finer, as denoted by the red arrow. The smaller the creep stress, the MA constituent has enough time to decompose, resulting in the finer MA constituent. In addition, microalloying strong carbide-forming elements $(\mathrm{Nb}$ and $\mathrm{Ti}$ ) were mainly dissolved into ferrite and bainite at room temperature, and the strengthening effect was comparatively small. The $\mathrm{C}$ obtained by the decomposition of the MA constituent could be combined with $\mathrm{Mo}, \mathrm{Nb}$ and $\mathrm{Ti}$ to generate dispersed particles at elevated temperature [23]. Therefore, nano-scale carbide particles precipitated during creep experiments at $600{ }^{\circ} \mathrm{C}$. They could enlarge the dislocation pinning and the grain boundary effects, being conducive to improving the strength of steel at high temperature.

With the increase in time, the number of nano-scale particles that precipitated increased first and then became stable. Plenty of nano-scale particles provided high-density sites to form dislocation pile-up. The period of the dislocation pile-up formation/relaxation became shorter under a constant external loading [32]. Therefore, the strain peak interval decreased with creep time under the creep stress of $184 \mathrm{MPa}$. As the applied stress increased, more time was needed to generate sufficient dislocation pile-up to offset the applied stress, resulting in a longer peak interval. When the applied stress increased to a certain value, the interaction effect between dislocation and solute or dislocation and precipitate was not sufficiently grave to cause the serration behavior.

Figure 9 shows the macroscopic morphology and fracture morphology of the specimen after the creep test under the stress of $316 \mathrm{MPa}$ at $600^{\circ} \mathrm{C}$. There was obvious necking at the fracture, which was consistent with the tensile curve. The fracture surface was dominated by deep dimples, which was typical microvoid coalescence ductile fracture being formed through the nucleation, growth, and coalescence of microvoids [33]. 

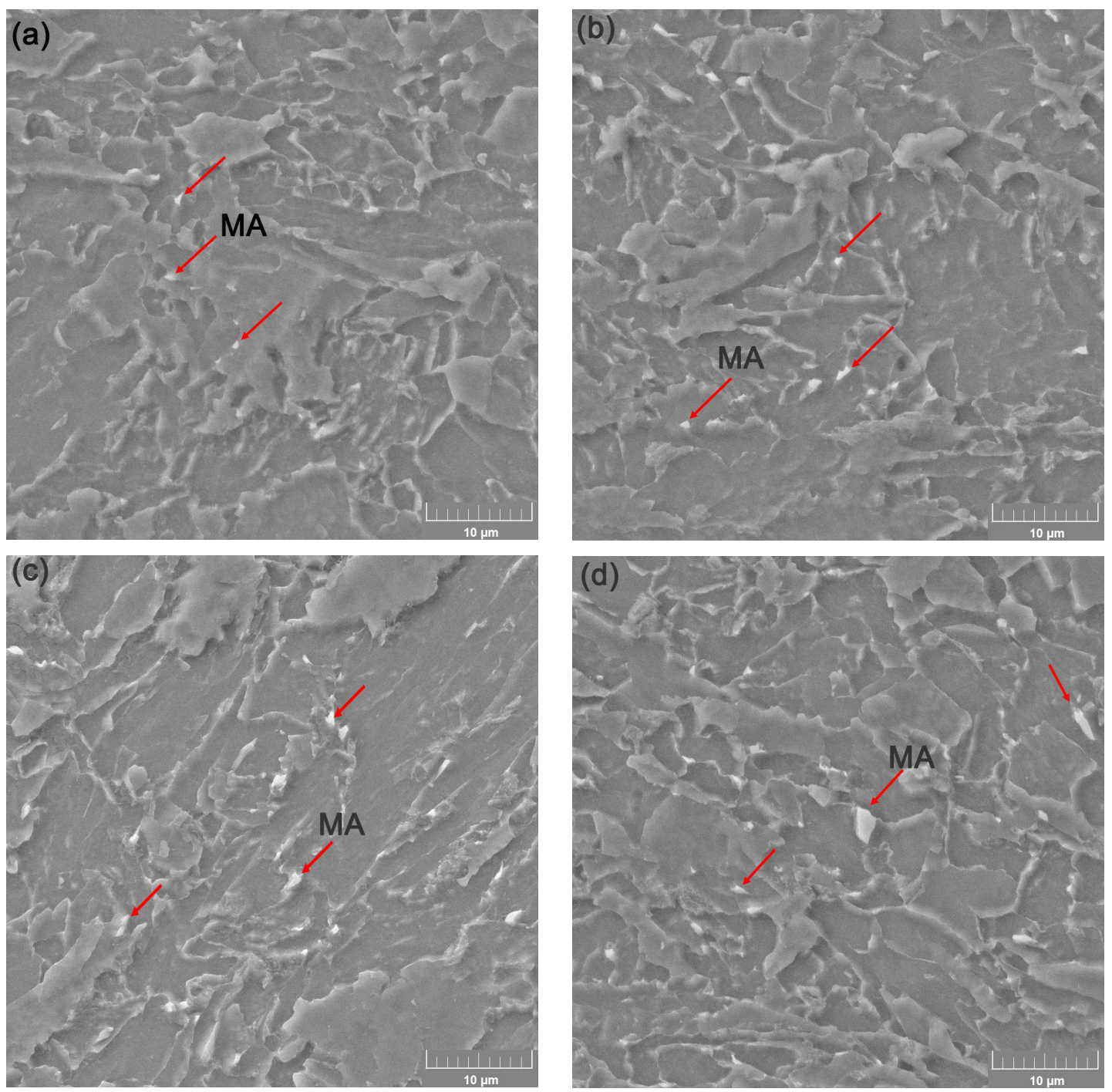

Figure 8. Microstructure of the Q460FRE steel after creep test under different stress: (a) $184 \mathrm{MPa}$, (b) $210 \mathrm{MPa}$, (c) $263 \mathrm{MPa}$, (d) $316 \mathrm{MPa}$.

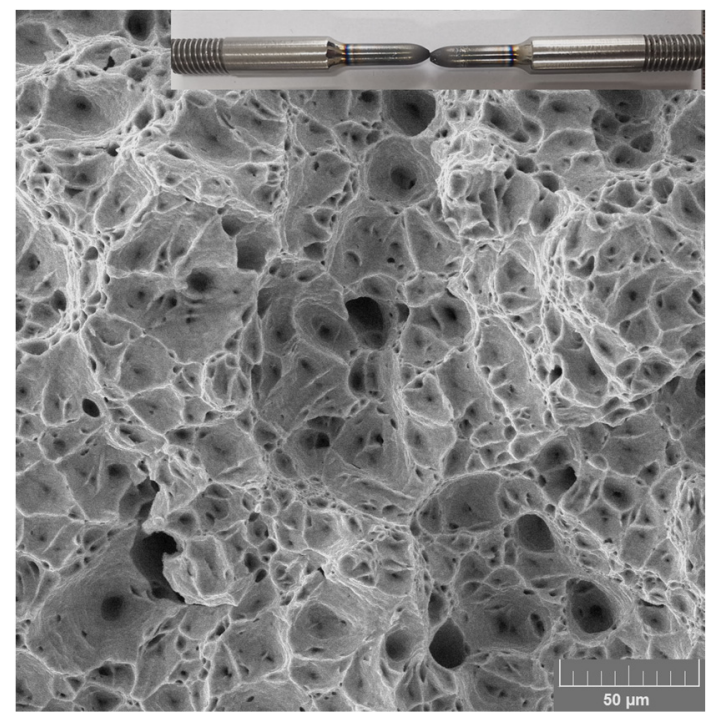

Figure 9. Fracture morphology of the specimen after creep test under the stress of $316 \mathrm{MPa}$ at $600{ }^{\circ} \mathrm{C}$. 


\subsection{Effect of Alternating Temperature on the Creep Behavior}

In order to simulate the effect of alternating fire temperature on the tensile properties of the Q460FRE steel, the creep experiments under heating and cooling cycles were carried out. The temperature varied between $600^{\circ} \mathrm{C}$ and $200{ }^{\circ} \mathrm{C}$, with a constant loading stress of $263 \mathrm{MPa}$, and a total of 120 heating and cooling cycles were undertaken in two hours. Due to the effect of thermal expansion and cold contraction, the creep strain of the specimen kept the same trend with the temperature, as shown in Figure 10. The specimen shrinks when cooled and elongates when heated. However, with the increase in creep time, the effect of cooling shrinkage was gradually weakened, and the creep strain increased. After two hours' creep test, the strain reached $0.31 \%$. Compared with the creep test at the constant temperature of $600{ }^{\circ} \mathrm{C}$, the creep strain was reduced by $87.3 \%$.

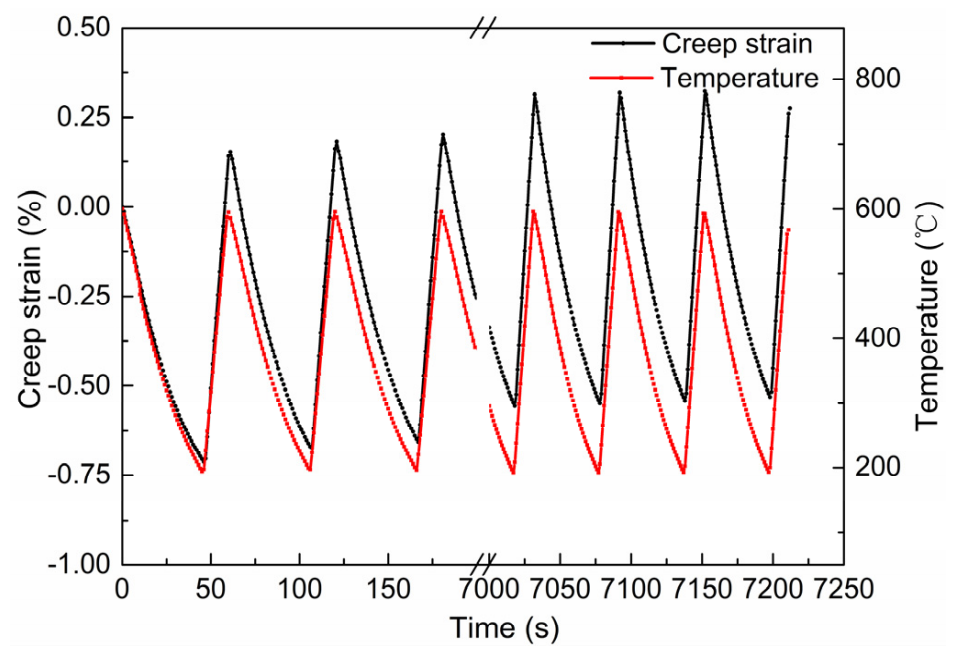

Figure 10. The creep strain-time and temperature-time curves under the stress of $263 \mathrm{MPa}$.

\subsection{Seismic Performance Characterized by the Internal Friction Analysis}

Internal friction-temperature spectra of the Q460FRE steel with different treated states are shown in Figure 11. The measurement spectra are composed of the background IF and the Snoek-Ke-Koster (SKK) peak [34]. With the increase in fire temperature, both the background IF and the SKK peak reduced gradually, showing a strong consistency. The result indicates that the damping capacity of the Q460FRE steel decreased gradually with the increase in fire temperature. The damping capacity of the steel was attributed to the amount of the grain-boundary precipitates, i.e., the less the precipitates, the higher the damping capacity [35].

The mechanism of the SKK peak was related to the interaction between interstitial carbon atoms and dislocation [36]. After simulating the fire process, interstitial carbon atoms and micro-alloy elements in steel were precipitated in the form of carbide, and the higher the temperature, the more precipitates. Figure 12 shows that the microstructures of the Q460FRE steel still composed of ferrite, bainite and MA constituent after holding at different temperature for $1 \mathrm{~h}$. The ferrite grain boundaries were clearly visible. However, $\mathrm{M} / \mathrm{A}$ components were gradually decomposed and refined with the increase in holding temperature, as denoted by the red arrows. During the heating process, the carbon enriched in the $\mathrm{M} / \mathrm{A}$ components could rapidly diffuse to the surrounding carbon-poor ferrite matrix and combined with $\mathrm{Mo}, \mathrm{Nb}$ and Ti to generate carbide precipitation at high temperature, leading to the gradual decomposition of M/A components [23,37]. The higher the temperature, the greater the diffusion driving force of carbon atoms, the more significant the decomposition of M/A components. Therefore, the carbon soluble in the matrix was reduced, leading to the decrease in the internal friction of the steel. 

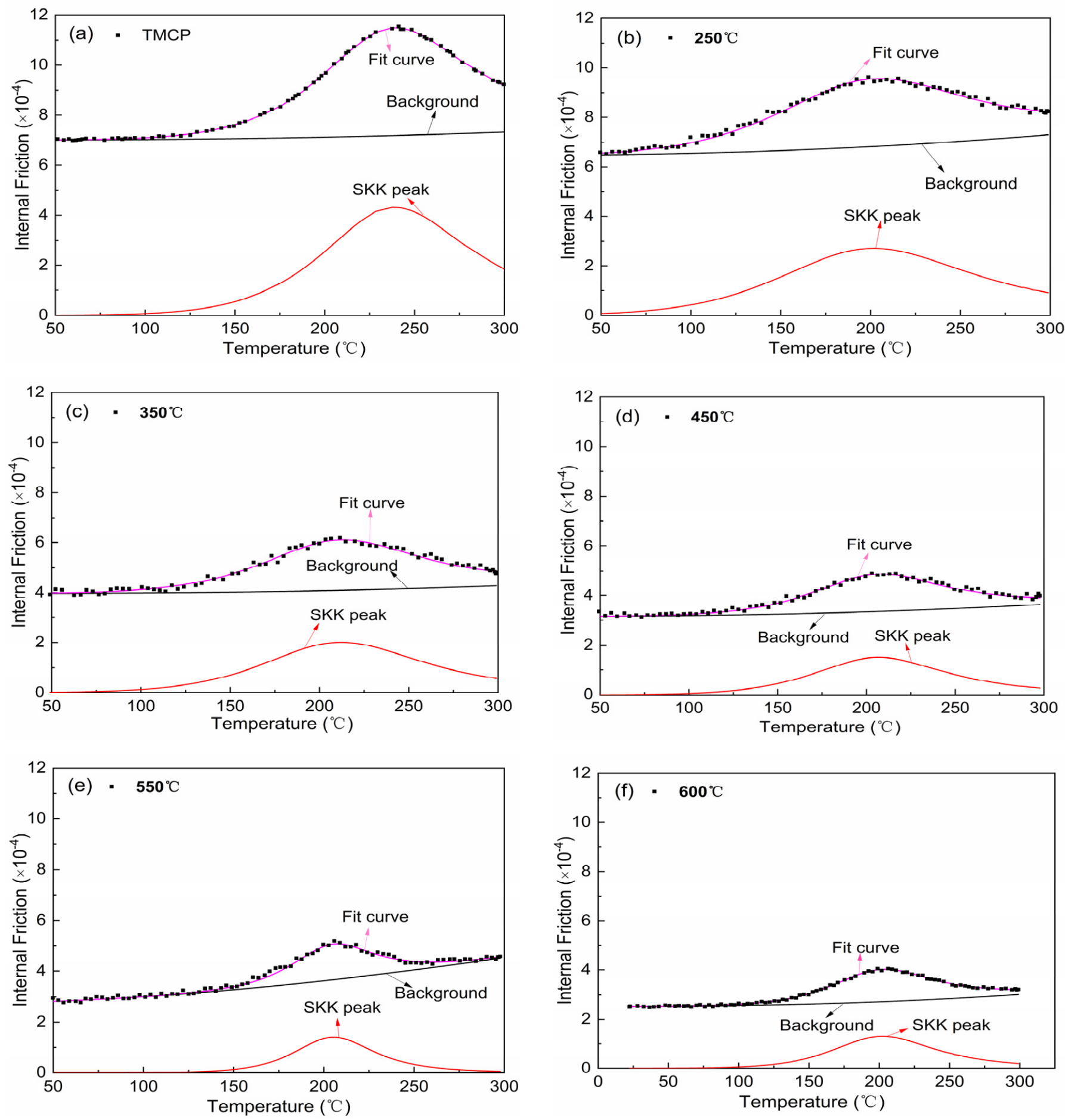

Figure 11. Internal friction-temperature spectra of the Q460FRE steel in TMCP state and after holding at different temperature: (a) $\mathrm{TMCP}$; (b) $250{ }^{\circ} \mathrm{C}$; (c) $350{ }^{\circ} \mathrm{C}$; (d) $450{ }^{\circ} \mathrm{C}$; (e) $550{ }^{\circ} \mathrm{C}$; (f) $600{ }^{\circ} \mathrm{C}$. 

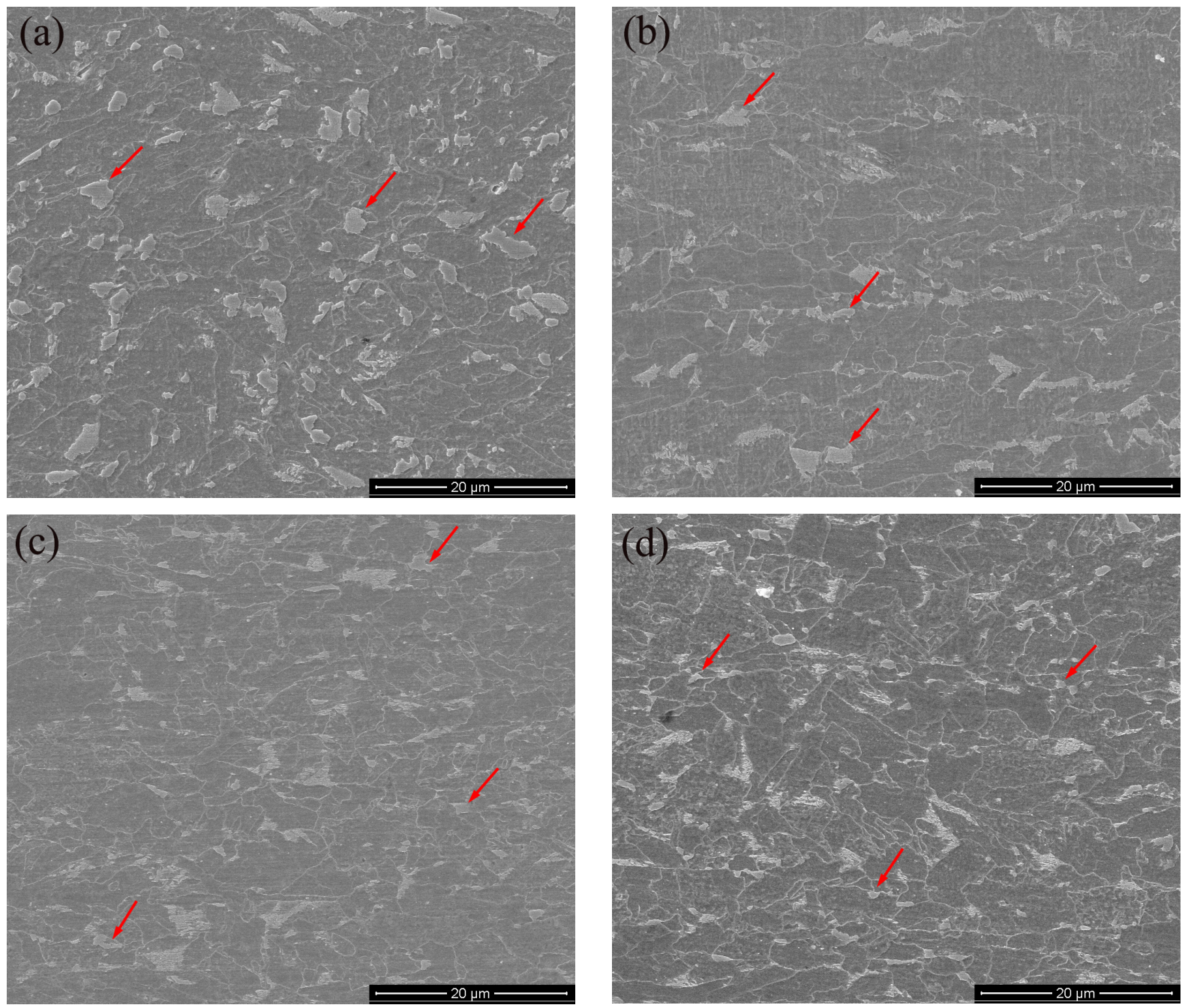

Figure 12. Microstructure of the Q460FRE steel after holding at different temperature for $1 \mathrm{~h}$ : (a) $250{ }^{\circ} \mathrm{C}$; (b) $350{ }^{\circ} \mathrm{C}$; (c) $450{ }^{\circ} \mathrm{C} ;$ (d) $600{ }^{\circ} \mathrm{C}$.

Compared with the measured values of the Q460FRE steel, the variation law of the seismic performance obtained from the internal friction test was consistent with that obtained from the yield ratio. As seen from Figure 13a and Table 2, with the increase in fire temperature, the internal friction of the Q460FRE steel at room temperature decreased continuously, and the yield ratio increased as a whole. Figure 13b shows the relationship between the IF value and the yield ratio of the Q460FRE seismic fire-resistant steel at room temperature. There was a linear relationship between the IF value and the yield ratio, indicating that it was feasible to use internal friction to characterize the seismic performance of steel. It requires the yield ratio of anti-seismic construction steel to be less than 0.85 [38], so the corresponding background IF value should be higher than $3.1 \times 10^{-4}$.

Table 2. Background IF value and yield ratio of the Q460FRE steel after holding at different temperatures.

\begin{tabular}{ccccccc}
\hline Temperature & $\mathbf{2 5}{ }^{\circ} \mathbf{C}$ & $\mathbf{2 5 0}{ }^{\circ} \mathbf{C}$ & $\mathbf{3 5 0}{ }^{\circ} \mathbf{C}$ & $\mathbf{4 5 0}{ }^{\circ} \mathbf{C}$ & $\mathbf{5 5 0}{ }^{\circ} \mathbf{C}$ & $\mathbf{6 0 0}{ }^{\circ} \mathbf{C}$ \\
\hline IF value $\left(\times 10^{-4}\right)$ & 6.86 & 6.46 & 5.97 & 3.15 & 2.72 & 2.52 \\
Yield ratio & 0.75 & 0.76 & 0.79 & 0.84 & 0.83 & 0.87 \\
\hline
\end{tabular}



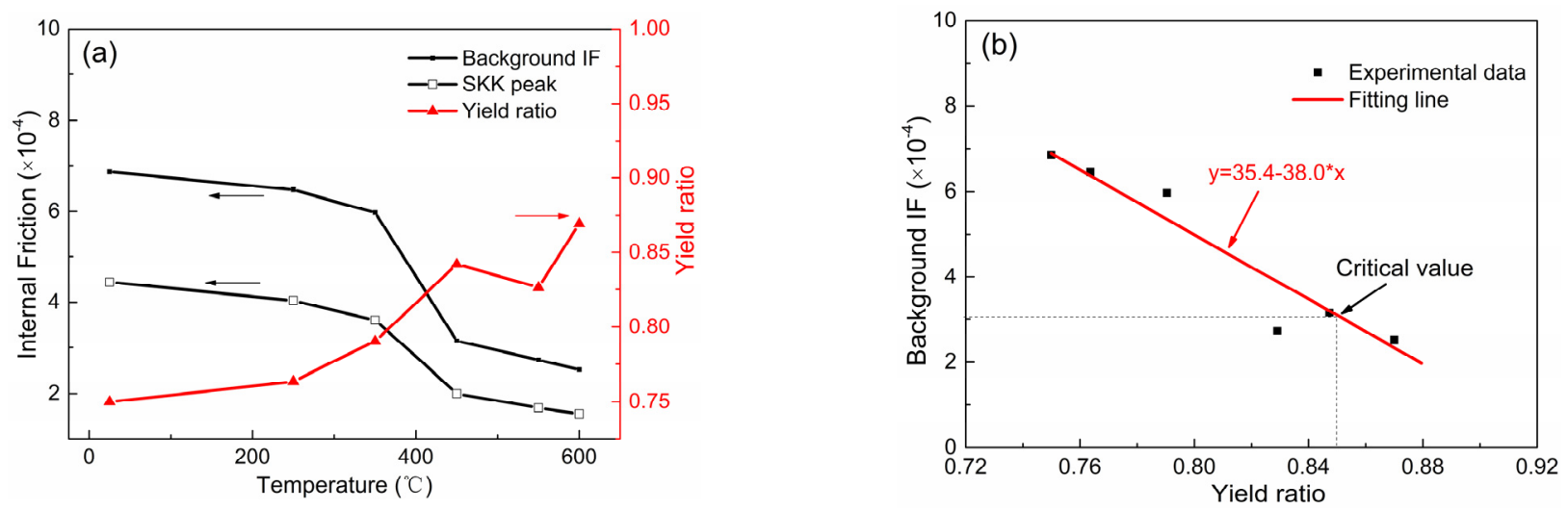

Figure 13. (a) Internal friction value and yield ratio of the steel held at different temperatures. (b) Relationship between background IF value and yield ratio.

\section{Conclusions}

In this work, the fire resistance and seismic performance of a high-strength construction steel Q460FRE were investigated by creep and internal friction test. The following conclusions were obtained:

(1) The Q460FRE steel exhibited better fire resistance than conventional structural steel, and the yield strength at $600{ }^{\circ} \mathrm{C}$ was $67.4 \%$ of the yield strength at room temperature.

(2) The constitutive equation of creep stress and fracture time at $600{ }^{\circ} \mathrm{C}$ was established. The bearing tensile stress of the Q460FRE steel should be lower than $337 \mathrm{MPa}$ to ensure at least 1 hour of evacuation time. The serration behavior of the creep strain was related to the dislocation-solute interactions and dislocation-precipitate interactions.

(3) Due to the effect of thermal expansion and cold contraction, the creep strain increased with fluctuation at alternating temperature and was lower than that of the creep test at the constant temperature of $600^{\circ} \mathrm{C}$.

(4) An internal friction test could be used well to evaluate the seismic performance of steel. The damping capacity of the Q460FRE steel decreased with the increase in fire temperature, which was consistent with the analysis results of the seismic performance characterized by the yield ratio.

Author Contributions: Methodology and supervision, Y.H.; project administration, Z.Y. and Z.L.; writing - original draft, Z.X. and X.D.; investigation, Z.X. and L.Y.; data curation, X.J. All authors have read and agreed to the published version of the manuscript.

Funding: This research was funded by National Key R\&D Program of China (grant no. 2017YFB0304700, no. 2017YFB0304702).

Institutional Review Board Statement: Not applicable.

Informed Consent Statement: Not applicable.

Data Availability Statement: All data that support the findings of this study are included within the article.

Conflicts of Interest: The authors declare no conflict of interest.

\section{References}

1. Xiong, M.-X.; Liew, J.Y.R. Experimental study to differentiate mechanical behaviours of TMCP and QT high strength steel at elevated temperatures. Constr. Build. Mater. 2020, 242, 118105. [CrossRef]

2. Kumar, W.; Sharma, U.K.; Shome, M. Mechanical properties of conventional structural steel and fire-resistant steel at elevated temperatures. J. Constr. Steel Res. 2021, 181, 106615. [CrossRef]

3. Li, G.-Q.; Wang, X.-X.; Zhang, C.; Cai, W.-Y. Creep behavior and model of high-strength steels over $500 \mathrm{MPa}$ at elevated temperatures. J. Constr. Steel Res. 2020, 168, 105989. [CrossRef]

4. Meißner, T.M.; Montero, X.; Fähsing, D.; Galetz, M.C. Cr diffusion coatings on a ferritic-martensitic steel for corrosion protection in KCl-rich biomass co-firing environments. Corros. Sci. 2020, 164, 108343. [CrossRef] 
5. Market for Fire-Resistant Coatings to Reach $\$ 1106$ Million by 2025. Focus Powder Coat. 2021, 2021, 7. [CrossRef]

6. Wan, R.; Sun, F.; Zhang, L.; Shan, A. Effects of Mo on high-temperature strength of fire-resistant steel. Mater. Des. 2012, 35, 335-341. [CrossRef]

7. Jo, H.-H.; Shin, C.; Moon, J.; Jang, J.H.; Ha, H.-Y.; Park, S.-J.; Lee, T.-H.; Lee, B.H.; Chung, J.-H.; Speer, J.G.; et al. Mechanisms for improving tensile properties at elevated temperature in fire-resistant steel with Mo and Nb. Mater. Des. 2020, $194,108882$. [CrossRef]

8. Huo, X.; Xia, J.; Li, L.; Peng, Z.; Chen, S.; Peng, C.-T. A review of research and development on titanium microalloyed high strength steels. Mater. Res. Express 2018, 5, 062002. [CrossRef]

9. Xie, Z.; Song, Z.; Chen, K.; Jiang, M.; Tao, Y.; Wang, X.; Shang, C. Study of Nanometer-Sized Precipitation and Properties of Fire Resistant Hot-Rolled Steel. Metals 2019, 9, 1230. [CrossRef]

10. Sha, W. The Behaviour of Structural Steels at Elevated Temperatures and the Design of Fire Resistant Steels. Mater. Trans. 2001, 42, 1913-1927. [CrossRef]

11. Chijiiwa, R.; Yoshida, Y.; Uemori, R.; Tamehiro, H.; Funato, K.; Horii, Y. Development and Practical Application of Fire-Resistant Steel for Buildings; Nippon Steel Corporation: Tokyo, Japan, 1993; pp. 47-55.

12. Zhang, Z.-y.; Yong, Q.-1.; Sun, X.-j.; Li, Z.-d.; Kang, J.-y.; Wang, G.-d. Microstructure and Mechanical Properties of Precipitation Strengthened Fire Resistant Steel Containing High $\mathrm{Nb}$ and Low Mo. J. Iron Steel Res. Int. 2015, 22, 337-343. [CrossRef]

13. Shi, Y.; Tu, C.; Wu, Y.; Liu, D.; Meng, L.; Ban, H. Numerical investigations of fire-resistant steel welded I-section columns under elevated temperatures. J. Constr. Steel Res. 2021, 177, 106464. [CrossRef]

14. Zhang, S.; Shen, J.; Kang, H.; Hu, F. Study on creep behavior and microstructure of a Fe-Cr-Al-Nb-W ferrtic heat-resistant steel based on C, N and Al element control. Mater. Res. Express 2020, 7, 056524. [CrossRef]

15. Wang, J.; Fa, Y.; Tian, Y.; Yu, X. A machine-learning approach to predict creep properties of Cr-Mo steel with time-temperature parameters. J. Mater. Res. Technol. 2021, 13, 635-650. [CrossRef]

16. Torić, N.; Boko, I.; Divić, V.; Burgess, I.W. Behaviour of Steel Grade S275JR Columns under the Influence of High-Temperature Creep. Metals 2018, 8, 874. [CrossRef]

17. Chen, Y.; Li, Y.; Zhou, X.; Tan, F.; Jiang, Y. Effects of cryogenic treatment on mechanical properties and crystal orientation of 0.25C-0.80Si-1.6Mn steel with extraordinary strength-toughness. Mater. Res. Express 2021, 8, 036517. [CrossRef]

18. Wang, M.; Fahnestock, L.A.; Qian, F.; Yang, W. Experimental cyclic behavior and constitutive modeling of low yield point steels. Constr. Build. Mater. 2017, 131, 696-712. [CrossRef]

19. Nowick, A.S. Internal friction in metals. Prog. Met. Phys. 1953, 4, 1-70. [CrossRef]

20. Lai, H.-H.; Cheng, H.-C.; Su, S.-H.; Lin, C.-M.; Wu, W. Evolution of internal friction in low-carbon steel during vibratory stress relief. J. Mater. Res. Technol. 2020, 9, 5403-5409. [CrossRef]

21. Dere, E.G.; Sharma, H.; Petrov, R.H.; Sietsma, J.; Offerman, S.E. Effect of niobium and grain boundary density on the fire resistance of Fe-C-Mn steel. Scr. Mater. 2013, 68, 651-654. [CrossRef]

22. Wang, W.Y.; Liu, B.; Kodur, V. Effect of Temperature on Strength and Elastic Modulus of High-Strength Steel. J. Mater. Civ. Eng. 2013, 25, 174-182. [CrossRef]

23. Wang, X.; Li, Z.; Zhou, S.; Wang, W.; Yong, Q.; Yang, Z.; Shen, J.; Shang, C.; Liu, Q. Precipitation behavior of Ti-Nb-V-Mo quaternary microalloyed high strength fire-resistant steel and its influence on mechanical properties. Mater. Sci. Eng. A 2021, 807, 140865. [CrossRef]

24. Xiao, B.; Xu, L.; Zhao, L.; Jing, H.; Han, Y.; Song, K. Transient creep behavior of a novel tempered martensite ferritic steel G115. Mater. Sci. Eng. A 2018, 716, 284-295. [CrossRef]

25. Choi, I.-C.; Yoo, B.-G.; Kim, Y.-J.; Jang, J.-I. Indentation creep revisited. J. Mater. Res. 2012, 27, 3-11. [CrossRef]

26. Lee, D.-H.; Seok, M.-Y.; Zhao, Y.; Choi, I.-C.; He, J.; Lu, Z.; Suh, J.-Y.; Ramamurty, U.; Kawasaki, M.; Langdon, T.G.; et al. Spherical nanoindentation creep behavior of nanocrystalline and coarse-grained CoCrFeMnNi high-entropy alloys. Acta Mater. 2016, 109, 314-322. [CrossRef]

27. Norton, B. The Creep of Steel at High Temperatures; McGraw Hill: London, UK, 1929.

28. Yavari, P.; Langdon, T.G. An examination of the breakdown in creep by viscous glide in solid solution alloys at high stress levels. Acta Metall. 1982, 30, 2181-2196. [CrossRef]

29. Monkman, F.C.; Grant, N.J. An empirical relationship between rupture life and minimum creep rate in creep-rupture tests. Proc. ASTM 1956, 56, 593-615.

30. Zhang, Y.; Liu, J.P.; Chen, S.Y.; Xie, X.; Liaw, P.K.; Dahmen, K.A.; Qiao, J.W.; Wang, Y.L. Serration and noise behaviors in materials. Prog. Mater. Sci. 2017, 90, 358-460. [CrossRef]

31. Li, X.; Holdsworth, S.R.; Mazza, E.; Hosseini, E. Creep behaviour of a high chromium martensitic steel under stress varying creep loading conditions: Primary creep regeneration (PCR). Int. J. Press. Vessel. Pip. 2020, 187, 104188. [CrossRef]

32. Li, X.; Holdsworth, S.R.; Mazza, E.; Hosseini, E. Comparison of primary creep regeneration and anelastic recovery behaviour of $316 \mathrm{H}$ austenitic and 10\%Cr martensitic steels. Mech. Mater. 2020, 148, 103474. [CrossRef]

33. Li, W.; Xie, D.; Li, D.; Zhang, Y.; Gao, Y.; Liaw, P.K. Mechanical behavior of high-entropy alloys. Prog. Mater. Sci. 2021, 100777. [CrossRef]

34. Li, W.; Cai, M.; Wang, D.; Zhang, J.; Zhao, S.; Shao, P. Studying on tempering transformation and internal friction for low carbon bainitic steel. Mater. Sci. Eng. A 2017, 679, 410-416. [CrossRef] 
35. Wang, W.; Zhou, B. The correlation of damping capacity with grain-boundary precipitates in Fe-Cr-based damping alloys annealed at high temperature. Mater. Sci. Eng. A 2004, 366, 45-49. [CrossRef]

36. Choi, W.S.; Lee, J.; De Cooman, B.C. Internal-friction analysis of dislocation-interstitial carbon interactions in press-hardened 22MnB5 steel. Mater. Sci. Eng. A 2015, 639, 439-447. [CrossRef]

37. Lan, L.; Yu, M.; Qiu, C. On the local mechanical properties of isothermally transformed bainite in low carbon steel. Mater. Sci. Eng. A 2019, 742, 442-450. [CrossRef]

38. ANSI/AISC SSPEC-2005 Seismic Provisions for Structural Steel. Available online: //www.aisc.org/globalassets/aisc/ publications/standards/seismic-provisions-for-structural-steel-buildings-ansi-aisc-341-16.pdf (accessed on 12 May 2021). 